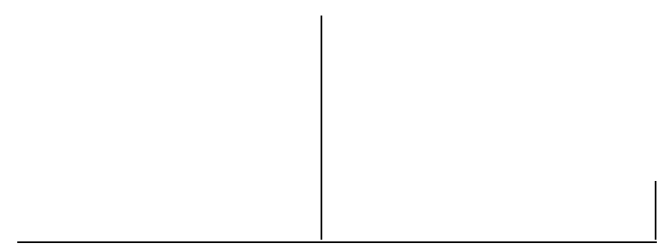

\title{
Estudo comparativo entre o quadro clínico contemporâneo "fibromialgia" e o quadro clínico "histeria" descrito por Freud no século XIX
}

\author{
Thais Krukoski Marques e Silva Slompo \\ Leda Mariza Fischer Bernardino
}

\begin{abstract}
Este trabalho tem como objetivo comparar o quadro clínico contemporâneo Fibromialgia, com o quadro clínico Histeria, tal qual descrito por Sigmund Freud no século XIX. Pretende-se explorar as duas patologias no que se refere à descrição, sintomas, fatos e tratamento. Serão também apresentados casos clínicos para ilustrar os dois quadros e identificar possíveis semelhanças. A fibromialgia será descrita através do discurso médico contemporâneo; já a histeria será abordada através dos escritos de Freud. Por fim, defende-se a hipótese de que a fibromialgia faz parte do quadro clínico da histeria, ou seja, que os sujeitos diagnosticados com fibromialgia são, na verdade, pacientes que apresentam sintomas histéricos.
\end{abstract}

Palavras-chave: Fibromialgia, histeria, psicanálise 


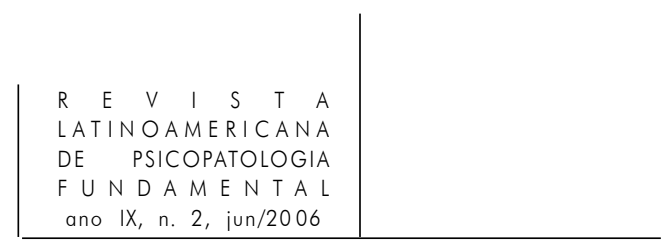

Que coisa estranha é para o sujeito ter corpo.

Clarice Lispector

\section{Introdução}

Este trabalho é um estudo comparativo do quadro clínico contemporâneo denominado "fibromialgia" e do quadro clínico da "histeria”, tal qual foi descrito por Sigmund Freud no século XIX.

Na fibromialgia - literalmente, dores nas fibras musculares - o sujeito é acometido por dores difusas pelo corpo. Em seus casos mais severos a dor é tão forte que paralisa. Não existem exames que diagnostiquem a síndrome; seu diagnóstico é baseado exclusivamente na queixa do paciente. O fato de um corpo aparentemente são, mas que dói a ponto de paralisar o sujeito, é realmente intrigante.

Intrigante também era a histeria para Freud: pacientes, na sua grande maioria mulheres, com sintomas físicos que não podiam ser explicados fisiologicamente. Enquanto a maior parte dos médicos tratava dessas mulheres com desdém, Freud se propôs a escutá-las, a partir da seguinte constatação: "Como se houvesse a intenção de expressar o estado mental através de um estado físico; e o uso lingüístico fornece uma ponte pelo qual isso pode ser efetuado" (Freud 1893, p. 43).

Freud percebeu que o sintoma físico era reflexo de um processo mental que há muito estava reprimido, e proporcionava a suas pacientes um lugar de escuta no qual esses sintomas eram trabalhados no sentido de encontrar seu estatuto de palavra.

Certamente, as mulheres que Freud ouvia não são as mesmas dos tempos atuais. Mais de um século se passou desde então; nem a mulher ocupa a mesma posição social que ocupava no final do século XIX, nem a sexualidade se apresenta do mesmo modo que à época da repressão vitoriana. Mas será que as questões sobre feminilidade e sexualidade mudaram tanto assim?

Curiosamente, cada vez mais novas patologias vêm sendo descritas, como se o sintoma roubasse, de novo, o lugar da palavra. 
Mas serão novas estas patologias? Ou apenas "repaginadas", com a cara do século XXI? Neste século do poderio econômico neoliberal, no qual a indústria dos medicamentos reina absoluta, são necessárias novas doenças para que se prescrevam novos medicamentos. Como afirma Charles Melman (2003), "os laboratórios hoje escrevem a clínica das afecções neuróticas e psicóticas” (p. 116).

A partir deste estudo pretende-se indagar qual é o lugar da fibromialgia nos dias atuais. Trata-se de uma questão para a medicina ou para a psicanálise?

Este trabalho se justifica pela sua importância social, clínica e ética. Nestes tempos em que a premissa do "medicar, ao invés do falar" impera com toda sua força, busca-se com a psicanálise um retorno ao Sujeito ( $($ ), ou seja: "ao invés de calar o sintoma; falar do sintoma”.

A hipótese que se pretende estudar durante o desenvolver deste trabalho é que a fibromialgia, tal como descrita nos dias de hoje, faz parte do quadro clínico da histeria, ou seja, que os sujeitos diagnosticados com fibromialgia são, na verdade, pacientes que apresentam sintomas histéricos.

\section{O quadro clínico "Fibromialgia” sob o ponto de vista médico}

A fibromialgia é uma síndrome crônica caracterizada por queixa dolorosa musculoesquelética difusa e pela presença de pontos dolorosos em regiões anatomicamente determinadas (Wolfe, 1990).

Outras manifestações que podem acompanhar o quadro são: fadiga crônica, distúrbio do sono, rigidez muscular, parestesias, cefaléia, síndrome do cólon irritável, fenômeno de Raynaud, assim como a presença de alguns distúrbios psicológicos, em especial ansiedade e depressão. A depressão, por sua vez, está presente em $25 \%$ dos casos de fibromialgia e $50 \%$ dos pacientes relatam antecedente depressivo (Hudson \& Pope, 1989).

Desde meados do século XIX já eram reconhecidas manifestações clínicas que sugeriam o diagnóstico de fibromialgia. Em 1850, Froriep publicou casos de pacientes que apresentavam contraturas musculares e dor a digitopressão em diversas regiões anatômicas, sem, no entanto, caracterizar a presença de pontos dolorosos. Em 1904, Gowers propôs o termo fibrosite para designar síndromes dolorosas sistêmicas, ou regionais, nas quais observou uma sensibilidade dolorosa aumentada em determinadas regiões anatômicas, com ausência de manifestações inflamatórias, sendo que a fadiga e distúrbios do sono eram, por vezes, relatados.

Durante as décadas de 1950 e 1960 o termo fibrosite foi utilizado de forma pouco específica, havendo diversos relatos de dores musculares referidas, uniformes quanto ao padrão das queixas, porém diferindo quanto aos locais acometidos. 


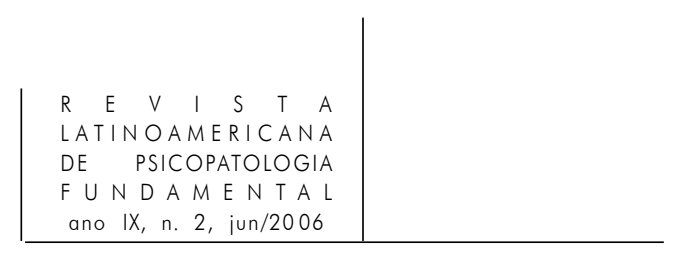

Muitos autores consideravam a fibrosite uma causa freqüente de dores musculares, enquanto outros acreditavam tratar-se de um reumatismo psicogênico relacionado à tensão emocional.

A fibromialgia não era considerada uma entidade até a década de 1970, quando Moldofsky (1975), publicou os primeiros relatos dos distúrbios do sono e dos achados polissonográficos, que deram margem a novas vertentes na investigação etiopatogênica. O termo fibromialgia foi proposto em 1976 por Hench, e em 1977, Smythe \& Moldofsky propuseram critérios para o seu diagnóstico. Os diversos estudos que surgiram, a partir de então, observaram que uma grande parte dos pacientes com fibromialgia apresentava, em comum, regiões anatômicas mais dolorosas salientando-se o epicôndilo lateral, a região costocondral e os grupamentos musculares da região cervical.

Na década de 1980, a questão dos critérios diagnósticos foi bastante debatida e consagrou-se a fibromialgia como uma entidade clínica.

Em 1990, o Colégio Americano de Reumatologia publicou um estudo multicêntrico, realizado em 16 centros especializados nos Estados Unidos e Canadá, por um período de quatro anos, que envolveu 293 pacientes com fibromialgia e 265 controles, que apresentavam condições clínicas facilmente confundíveis com a fibromialgia (Wolfe, 1990). Foram propostos, como critérios diagnósticos para a fibromialgia, a presença de queixas dolorosas difusas, abrangendo as regiões acima e abaixo da linha da cintura, bilateralmente, por um período maior do que três meses e a presença de dor em pelo menos 11 de 18 pontos anatomicamente padronizados. Considerou-se positivo um ponto, quando era referido desconforto doloroso no local, após digitopressão com intensidade de força equivalente ao limite e $4 \mathrm{kgf} / \mathrm{cm}^{2}$ com o uso de dolorímetro.

Os estudos epidemiológicos para a determinação da prevalência da fibromialgia são escassos (ibid., 1986), e até 1990 os dados eram conflitantes, devido às diferenças entre os padrões de referência de cada serviço, aos diferentes critérios diagnósticos utilizados, assim como às diferenças regionais entre as populações.

A freqüência da fibromialgia é de 1 a 5\% na população em geral (Jacobsson, 1989). Considerando os pacientes atendidos em clínica médica, a freqüência da fibromialgia é em torno de $5 \%$, o que corresponde a $2,1 \%$ dos atendimentos do médico de família e a $7,5 \%$ dos pacientes hospitalizados. Na clínica reumatológica, por sua vez, ela é detectada entre $14 \%$ e $20 \%$ dos atendimentos.

Na literatura nacional destaca-se o trabalho de Bianchi, Messias e Gonçalves (Seda, 1982), que observaram a freqüência de "fibrosite" em 10,2\% das populações do Rio de Janeiro e Porto Alegre. Martinez (1992), além de confirmar estes achados, evidenciou o impacto socioeconômico da fibromialgia já descrito por outros autores. 


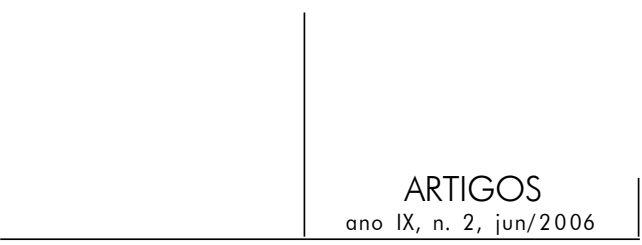

A fibromialgia é mais freqüente no sexo feminino, sendo 73 e $88 \%$ dos casos descritos nesse sexo. Em média, a idade do seu início varia entre 29 e 37 anos, sendo a idade de seu diagnóstico, entre 34 e 57 anos (Wolfe, 1990). Segundo o estudo multicêntrico realizado pelo autor, a média de idade por ocasião do diagnóstico foi de 49 anos, sendo 89\% mulheres e 93\% caucasianos.

As manifestações da fibromialgia tendem a ter início insidioso na vida adulta, no entanto, 25\% dos casos referem apresentar os sintomas dolorosos desde a infância (Wolfe, 1986).

A origem da fibromialgia está relacionada à interação de fatores genéticos, neuroendócrinos, psicológicos e distúrbios do sono (Moldofsky, 1989). As alterações nos mecanismos de percepção de dor atuam como fator que predispõe o indivíduo à fibromialgia, frente a processos dolorosos, a esforços repetitivos, à artrite crônica, a situações estressantes como cirurgias ou traumas, processos infecciosos, condições psicológicas e até retirada de medicações, como corticosteróides (Yunus, 1994).

Tem-se observado que os indivíduos com fibromialgia, além de apresentarem os característicos pontos dolorosos, apresentam também aumento da sensação dolorosa em pontos ditos controle (Quimby, 1988).

A deficiência de serotonina, em particular, está implicada nas síndromes dolorosas periféricas e centrais, levando a hiperalgesia. Além disto, a serotonina e outras aminas biogênicas alteram a função dos macrófagos, ativam as células citotóxicas e atuam em musculatura lisa, inclusive a dos vasos, mecanismo que pode participar dos fenômenos vasoativos e da síndrome do cólon irritável presentes na fibromialgia (Bennet, 1993). A liberação de substância P, por sua vez, é influenciada pela serotonina e a sua deficiência, quer no sistema nervoso periférico, quer no central, acarreta alterações na percepção de estímulos sensitivos normais (Russel, 1989). Nas situações em que ocorre depleção de serotonina, observa-se a diminuição do sono não REM e o aumento das queixas dolorosas, psicossomáticas e depressivas.

A principal queixa dos pacientes com fibromialgia é a dor difusa e crônica, muitas vezes difícil de ser localizada ou caracterizada com precisão (Goldenberg, 1987). Os distúrbios do sono e a fadiga são relatados por $75 \%$ dos casos (Wolfe, 1990), fadiga esta que tem início logo ao despertar e duração maior do que uma hora, reaparecendo no meio da tarde. Os pacientes referem, ainda, rigidez matinal e sensação de sono não restaurador, apesar de terem dormido de 8 a 10 horas. O sono é superficial, tendo os pacientes facilidade de acordar frente a qualquer estímulo, além de apresentar um despertar precoce (Moldofsky, 1989).

Apesar de poder apresentar-se de forma extremamente dolorosa e incapacitante, a fibromialgia não ocasiona comprometimento articular inflamatório ou restritivo (Wolfe \& Cathey, 1983). A presença dos pontos dolorosos é o achado 


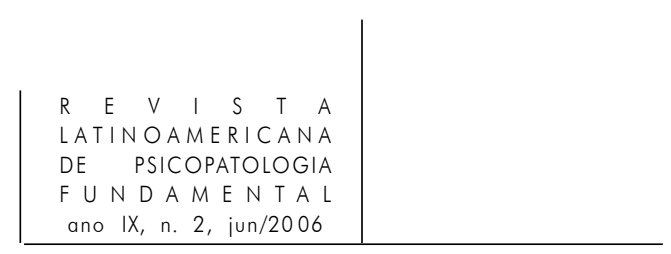

primordial do exame físico, não se observando edema ou sinovite, a não ser na concomitância de patologias como a osteoartrite ou artrite reumatóide.

A fraqueza muscular, o adormecimento e tremor em extremidades, embora referidos por $75 \%$ dos pacientes, não são comprovados ao exame neurológico, que é normal (Simms \& Goldenberg, 1988).

Na fibromialgia o limiar doloroso médio dos pontos padronizados, assim como dos pontos controle é mais baixo do que em outras doenças reumáticas (Wolfe, 1990).

Outros achados do exame físico incluem o espasmo muscular localizado, referidos como nódulos, a sensibilidade cutânea ao pregueamento (alodinia) ou dermografismo, após compressão local. A sensibilidade ao frio também pode estar presente e manifestar-se como "cutis marmorata" em especial nos membros inferiores (ibid.).

Os exames laboratoriais e o estudo radiológico são normais e, mesmo quando alterados, não excluem o diagnóstico de fibromialgia, uma vez que esta pode ocorrer em associação a artropatias inflamatórias, a síndromes cervicais ou lombares, as colagenoses sistêmicas, a síndrome de Lyme e a tireoidopatias (ibid.).

De uma forma geral o tratamento da fibromialgia repousa sobre quatro pilares: exercícios para alongamento e fortalecimento muscular, assim como para condicionamento cardiorespiratório; técnicas de relaxamento para prevenir espasmos musculares; hábitos saudáveis para melhorar a qualidade de vida e reduzir o estresse. Os pacientes com fibromialgia devem ter conhecimento pleno de sua condição clínica, uma vez que ela se caracteriza por recidivas intermitentes dos sintomas de dor e fadiga; medicações para o controle da dor e dos distúrbios do sono. O tratamento medicamentoso inclui a prescrição de antiinflamatórios e aspirina, antidepressivos tricíclicos; inibidores da recaptação da serotonina; benzodiazepínicos; medicações para o sono; medicações tópicas; analgésicos; e derivados de anticonvulsivantes.

\section{O quadro clínico "Histeria” segundo os estudos de Freud}

O termo histeria tem origem nos primórdios da medicina e resultou do preconceito, que vinculava as neuroses às doenças do aparelho sexual feminino ( $\nu \delta \tau \varepsilon \rho \alpha$, útero).

Segundo Freud (1888), a histeria é uma neurose no mais estrito sentido da palavra - que dizer, não só não foram achadas nessa doença alterações perceptíveis do sistema nervoso, como também não se espera que qualquer 


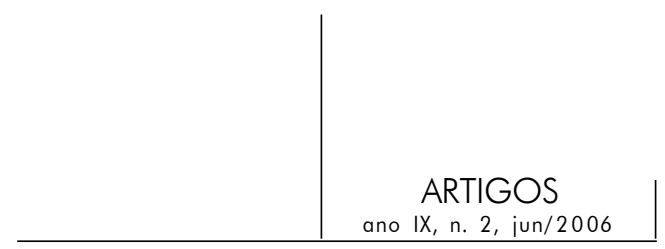

aperfeiçoamento das técnicas de anatomia venha revelar alguma dessas alterações. (ibid.).

Freud percorreu um longo caminho até apresentar a teoria da etiologia das neuroses tal qual a conhecemos, pois sua teoria foi sendo construída na medida em que sua clínica avançava.

No início de seus estudos sob a orientação de Charcot, Freud baseava sua clínica da histeria nos métodos comumente utilizados na época, o principal deles sendo a hipnose.

Sob a influência de Charcot e Janet tomava a histeria como uma “doença por representação”, e seria causada pela ação patogênica de uma representação psíquica, de uma idéia inconsciente e intensamente carregada de afeto que estava reprimida. Em “Comunicação preliminar” (1893), texto que antecede os “Estudos sobre a histeria” é essa a principal posição teórica adotada por ele:

... no curso normal das coisas, se uma experiência for acompanhada de uma grande dose de “afeto", esse afeto é “descarregado" numa variedade de atos reflexos conscientes, ou então vai se desgastando gradativamente pela associação com outros materiais mentais conscientes. No caso dos pacientes histéricos, por outro lado, nenhuma dessas coisas acontecem. O afeto permanece num estado "estrangulado, e a lembrança da experiência a que está ligado é isolada da consciência. A partir daí, a lembrança afetiva se manifesta em sintomas histéricos, que podem ser considerados "símbolos mnêmicos" - vale dizer, símbolos da lembrança suprimida. (p. 22)

No texto “A etiologia da histeria”, de 1896, Freud diz que "nenhum sintoma pode emergir de uma única experiência real, mas que em todos os casos, a lembrança de experiências mais antigas despertadas em associação com ela atua na causação do sintoma” (p. 194).

Mais adiante, continua dizendo que: “... a descoberta mais importante a qual chegamos quando uma análise é sistematicamente conduzida é que qualquer que seja o caso, qualquer que seja o sintoma que tomemos como ponto de partida, no fim chegamos infalivelmente ao campo da experiência sexual” (p. 196). Aqui, portanto, Freud trata pela primeira vez de uma precondição etiológica dos sintomas histéricos - um trauma de origem sexual.

Porém, Freud não pôde encontrar nenhum indício de que esses traumas pudessem ter sido causados pelas cenas da puberdade ou por cenas posteriores. Procurou, então, determinantes destes sintomas em experiências que retrocedessem ainda mais; ao fazer isso, chegou ao período da primeira infância. E expõe a tese de que "na base de todos os casos de histeria, há uma ou mais ocorrências de experiência sexual prematura, ocorrência reproduzida através do trabalho da psicanálise a despeito das décadas decorridas no intervalo” (Freud, 1896, p. 200). 


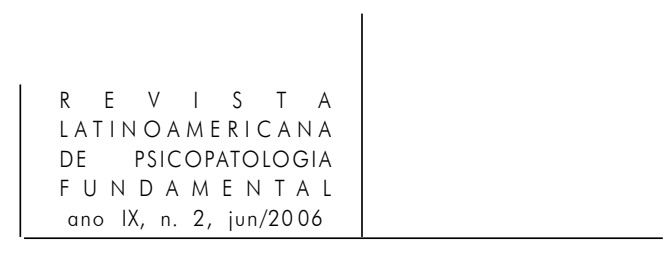

Nessa época Freud estava convencido de que o doente histérico havia sofrido, durante sua infância, uma experiência traumática. A criança fora vítima impotente de uma sedução sexual efetuada por um adulto. Acreditava que a etiologia da histeria devia-se a um trauma sexual sob a forma de sedução por parte do pai. Como afirma em sua Carta 52 (1896): “... a histeria resulta em todos os casos da perversão por parte do sedutor”. Acreditava, então, que o desejo do pai era sempre o elemento patogênico.

Tal hipótese foi abandonada na medida em que se deu conta de que não existe "índice de realidade" no inconsciente, de que não se pode distinguir entre a verdade e a ficção investida de afeto. Foi com a famosa frase dita na carta 69 a Fliess "não acredito mais em minha neurótica" que Freud conta com desapontamento os motivos pelos quais desacreditou na teoria de perversão por parte do pai (Freud, Carta 69, 1897):

... veio a surpresa diante do fato de que, em todos os casos, o pai, não excluindo o meu, tinha de ser apontado como pervertido - a constatação da inesperada freqüência da histeria, na qual o mesmo fator determinante é invariavelmente estabelecido, embora uma dimensão tão difundida da perversão em relação às crianças não seja muito provável. (A perversão teria de ser mais incomensuravelmente freqüente do que a histeria...). (p. 310)

Foi entre 1897 e 1905 que a teoria traumática da histeria - que Freud havia desenvolvido com o auxílio de Breuer - deu lugar à teoria da fantasia, na qual o atentado sexual sofrido foi tomado como uma elaboração fantasística que tinha efeito traumático. E a premissa de que "o desejo do pai é sempre o elemento patogênico" deu lugar à hipótese de que: “o desejo pelo pai, recalcado que estaria na origem da histeria” (Teoria do Édipo).

Assim como sua teoria, o tratamento da histeria também sofreu modificações. A hipnose utilizada por Freud no início de sua clínica logo deu lugar à técnica da "associação livre”, e a cura pela fala é utilizada no método psicanalítico.

Os seguintes sintomas histéricos foram descritos por Freud em seus estudos: abulia, afasia, alucinação, amaurose, ambliopia, amnésia, analgesia, anestesia, angústia, anorexia, artralgia, asma, astasia, atetose, attitudes passionelles; cãibras no pescoço, Cephalagia adolescentium, choro, contração de dedos das mãos e dos pés, contraturas, convulsões epileptóides, Délire ecmnésique, delírios, depressão, desmaios, diplopia, dispnéia, distúrbio do andar, distúrbios auditivos, distúrbio da fala, distúrbio do olfato, distúrbio da visão, dor de cabeça, dores gástricas, ecmnésia, enxaqueca, eritema, espasmos, espasmos clônicos, espasmos histéricos, estrabismo, estupor, euforia, fadiga, sensação de frio, gagueira, constriç̧ão da garganta, hemianestesia, hiperalgesia, hiperestesia, idées fixes; 


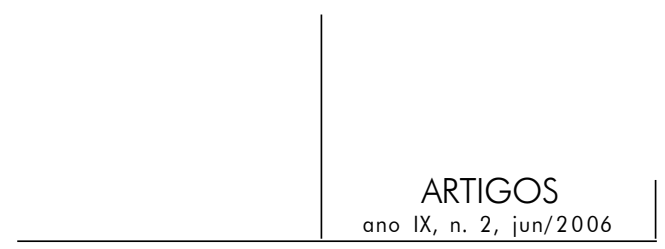

insônia, macropsia, mutismo, nevralgia, nevralgia ovariana, palpitações, parafasia, paralisia, paramnésia, paresia, parestesia, petit-mal; pseudo-encefalite, pseudoperitonite, surdez, tiques, tontura, tremores, Tussis nervosa, vômito, zoopsia (1895, p. 341).

Pode-se destacar, portanto, os sintomas comuns apresentados no quadro clínico “Fibromialgia” e no quadro clínico “Histeria”: angústia, choro, depressão, distúrbio do andar, dor de cabeça, espasmos, fadiga, insônia, nevralgia, parestesia e tremores.

\section{Os casos clínicos de histeria descritos por Freud}

Em “Estudos sobre a histeria”, Freud apresenta cinco casos clínicos e faz uma descrição bastante minuciosa e rica em detalhes tanto dos inúmeros sintomas que acometiam suas pacientes, como de fatos e detalhes de suas vidas. É nesse texto que se encontra a constatação principal, para sua teoria, de que o histérico sofre de reminiscências inconscientes, ligadas a um afeto insuportável que lhe serve de base mais tarde para o entendimento da sexualidade humana como infantil e ancorada nas fantasias edipianas.

No Caso I, de Anna O., 21 anos, os sintomas descritos são: dores de cabeça; contratura e anestesia das extremidades; sentimento de angústia, sendo marcantes o seguintes fatos de sua história: dedicou toda sua energia para cuidar do pai que veio a falecer; ajudava pobres e doentes; era conhecida pela bondade e consideração para com os outros; um dos seus traços de caráter era a generosidade e solidariedade.

No Caso II, de Emmy von N., 40 anos, os sintomas descritos são: depressão; insônia; dores por todo corpo; sensação de frio e dor na perna. De sua história, diz ter sido perseguida pelos parentes do marido; e as expectativas de infortúnios que não paravam de atormentá-la.

No Caso III, da srta. Lucy R., 30 anos, os sintomas são: depressão; fadiga; analgesia geral.

No Caso IV, da srta. Katharina, 18 anos, os sintomas são: "nervos ruins"; falta de ar; crises de angústia - acha que vai morrer; zumbido na cabeça.

Finalmente, no Caso V, da srta. Elizabeth Von R., os sintomas são: dores de caráter indefinido; fadiga dolorosa; dores irradiantes; músculos sensíveis à dor; hiperalgia muscular; fibras endurecidas. De sua história, destaca-se que sentiase responsável pela felicidade da mãe; e que cuidou do pai enfermo até a sua morte.

Em todos esses casos, Freud apresenta como, a partir da associação livre, com a rememoração dos fatos traumáticos que remetem à experiências sexuais 


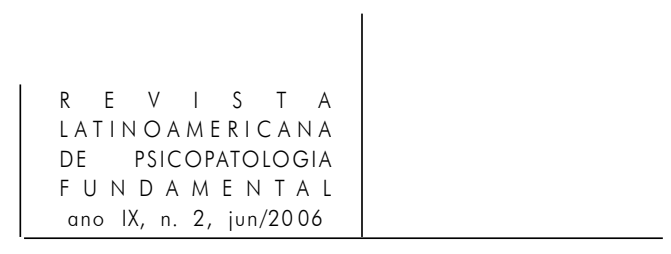

infantis recalcadas, os sintomas que se manifestam no corpo, ao se transcreverem em palavras para o psicanalista, têm uma outra resolução, desta vez simbólica.

\section{Casos clínicos de Fibromialgia}

Os pacientes fibromiálgicos foram ouvidos em entrevistas abertas, com duração de 50 minutos, realizadas no Ambulatório de Fibromialgia do Hospital de Clínicas da Universidade Federal do Paraná, entre dezembro de 2003 e março de 2004. Os pacientes ouvidos eram indicados pelos médicos do serviço, após terem passado pela consulta diagnóstica ou pela consulta de retorno.

Durante a entrevista os pacientes foram ouvidos sobre sua dor ou apenas convidados a falar sobre si. A entrevista tinha o intuito de redirecionar a queixa do paciente, que é estritamente física, fazendo com que eles dessem um novo sentido à sua dor. Assim como Freud (1896) descreve seu método de investigação anamnésica: "a que influências danosas os próprios pacientes atribuem seu adoecimento e o desenvolvimento desses sintomas” (p. 189).

Os sintomas físicos descritos por esses pacientes eram geralmente os mesmos, diferenciando-se apenas de membro ou intensidade; cada paciente, porém, tinha sua história, sua dor particular. A partir daí, dando lugar às queixas físicas, surgiram muitas histórias de vidas sofridas, e a dor do corpo se transformava em palavras, enfim, histórias que pareciam se repetir uma atrás da outra...

Traços recorrentes: pessoas que cuidam de tudo e todos; que se sentem responsáveis pela felicidade do outro; que sofreram perdas financeiras ou de saúde; situações de pai, marido violento; gravidez precoce; alcoolismo; abusos físicos, verbais, como pode-se perceber nos seguintes recortes da fala de alguns dos pacientes ouvidos no Ambulatório de Fibromialgia.

L.R. 48 anos, que sempre cuidou do marido doente e que agora sofre com a fibromialgia, diz: "agora que estou cada vez pior ele está cada vez melhor".

E.K. 45 anos, cuidou da sogra esclerosada de quem sofreu abusos físicos e verbais por 13 anos, além de cuidar dos filhos, da lavoura. Hoje diz sofrer por não poder mais dar conta de tudo, a dor física a impede.

A.M. 52 anos, descreve ter pertencido a uma cadeia de abusos, primeiro sofria com o pai alcoólatra, depois com o marido violento, agora é do chefe que reclama. Diz sempre ter conseguido dar conta de tudo, criou seus filhos sozinha, no momento as dores da fibromialgia a tem impedido.

C.S. 43 anos, descreve perdas financeiras sofridas há mais de vinte anos como se tivessem ocorrido há poucos dias, sofre com suas reminiscências da falência no corpo com a fibromialgia. 
O.A. 48 anos, conta seus partos difíceis, no último deles diz ter sido atendida por um médico sem experiência, “açougueiro”, que agora seus intestinos estão colados e que lhe doem muito, tudo dói.

T.M. 35 anos, conta ter sofrido cinco acidentes de carro durante a vida; no primeiro deles tinha apenas poucos dias de nascida. No mais grave, onde foi atropelado "pelas costas" por um amigo, ficou de cama por meses. Conta que sofre perseguições políticas e que isso destruiu a sua vida. Tem depressão e trabalha "drogado" para agüentar seu corpo doído.

M.L. 53 anos, quer sempre dar conta de tudo e de todos, não pode ver ninguém sofrendo e diz: "eu sinto na carne pelo outro". Descreve o sofrimento do outro colado em seu próprio corpo.

\section{Conclusão}

Durante o desenvolvimento deste trabalho pôde-se destacar várias semelhanças entre as duas patologias estudadas.

Segundo Moldofsky (1991), a origem da fibromialgia está relacionada à interação de fatores genéticos, neuroendócrinos, psicológicos e distúrbios do sono. Cita que diferentes fatores isolados ou combinados podem favorecer a manifestação do quadro, dentre eles doenças graves, traumas emocionais ou físicos. Freud (1895), antes de ligar a causa da histeria à pulsão sexual, também relacionava o aparecimento da histeria a traumas psíquicos.

Outro ponto em comum das duas patologias é o descrédito que ambas inicialmente provocaram e ainda provocam frente aos médicos. Afinal, o diagnóstico das duas doenças se dá exclusivamente pelas sensações relatadas pelos pacientes, não existindo nenhum exame que possa comprovar a veracidade do que é descrito.

Freud (1909), descreve:

... com o rótulo de histeria pouco se altera, portanto, a situação do doente, enquanto para o médico tudo se modifica. Pode-se observar que este se comporta para com o histérico de modo completamente diverso que para com o que sofre de uma doença orgânica. Nega-se conceder ao primeiro o mesmo interesse que dá ao segundo, pois não obstante as aparências, o mal daquele é muito menos grave. Os histéricos ficam privados da simpatia dos médicos, pois esses os consideram transgressores das leis de sua ciência. (p. 29)

Essa citação de Freud nunca foi tão atual, os sintomas histéricos continuam sendo tratados com a mesma falta de simpatia por alguns médicos como eram no final do século XIX. Esse mesmo preconceito encontra-se descrito na literatura 


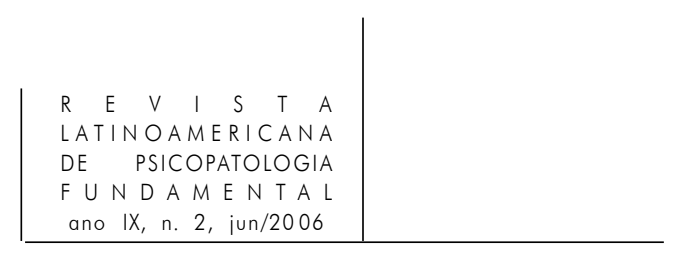

sobre fibromialgia. Hudson (1989) relata que pessoas que apresentavam dor generalizada e uma série de queixas mal-definidas não eram levadas a sério e que seus sintomas eram tomados por alguns como imaginários ou desprezíveis, e cita que ainda hoje tais sintomas dividem opiniões.

Como afirma Melman (2003), “... sempre foi uma particularidade histérica colocar dores na cena clínica, que não têm fundamento orgânico. É uma tradição absolutamente milenar" (p. 115).

Retomemos os sintomas da fibromialgia: dores difusas pelo corpo, fadiga crônica, distúrbio do sono, rigidez muscular, parestesias, cefaléias, síndrome do cólon irritável, fenômeno de Raynaud e distúrbios psicológicos, especialmente a ansiedade e a depressão. Agora voltemos a Freud (1895), em seus "Estudos sobre a histeria”: todos esses sintomas aparecem lá, assim descritos um a um.

E as histórias de vida das pacientes ouvidas por Freud no final do século XIX e as das pacientes ouvidas no ambulatório, será que diferem tanto assim?

Tratam-se de histórias de vidas sofridas, perdas, prazeres abdicados... pessoas que parecem querer dar conta do sofrimento do outro e do seu. Como se "seu corpo doído fosse o resultado metafórico da surra que levaram da vida" (Calligaris, 2001).

Freud (1895) pressupunha que os pacientes histéricos possuíam uma excitabilidade anormal do aparelho relacionado com as sensações de dor. Quimby (1988), também descreve a maior sensibilidade dos pacientes fibromiálgicos frente a um estímulo doloroso.

Freud descobriu o papel fundamental que a sexualidade apresenta na etiologia da histeria, bem como as questões relacionadas à feminilidade. Tal fato parece ter relevância na fibromialgia, uma vez que por volta de $90 \%$ dos seus casos diagnosticados são de pacientes do sexo feminino.

Os distúrbios do sono relatados em $75 \%$ dos casos de fibromialgia (Wolfe, 1990), já eram sintomas abordados por Freud em seu texto "Sobre o mecanismo psíquico dos fenômenos histéricos” (1893).

Um movimento curioso constatado no transcorrer deste estudo relaciona-se aos tratamentos sugeridos às duas patologias e à transformação que eles sofreram no decorrer dos anos.

Em 1896, quando Freud se fixou em Viena para estabelecer sua clínica de doenças nervosas, iniciou o tratamento das histerias com os métodos comumente recomendados, como a hidroterapia, massagens e cura pelo repouso. Quando esses métodos se revelaram insatisfatórios ele voltou à hipnose. Porém pouco a pouco foi abandonando o hipnotismo, o que o fez ampliar ainda mais sua compreensão dos processos mentais, utilizando-se do método da associação livre.

Segundo Bennett (1993), além do tratamento medicamentoso sugerido para a fibromialgia, sugere-se que o paciente faça exercícios físicos, como 
hidroginástica e caminhadas, sendo indicadas também sessões de relaxamento. Um dos "novos" tratamentos sugeridos pelos médicos para fibromialgia é a hipnose!

Torna-se impossível não remeter às sessões de hidroterapia e à cura pelo repouso, indicadas pelos médicos em 1896. Resta uma interrogação: será que a hipnose também será abandonada, como Freud a abandonou dando lugar à cura pela palavra? Assim como a histeria se tornou uma entidade da psicanálise, tomará a fibromialgia o mesmo caminho? No ambulatório em que se realizou a pesquisa, mesmo partindo do pressuposto organicista e do tratamento medicamentoso, os médicos pareciam bastante aliviados em poder contar com uma profissional "psi" para direcionar os pacientes que, mesmo com a receita nas mãos, ainda insistiam em querer falar! Ou quando as histórias contadas eram por demais chocantes, tristes...

Por fim, após abordar as duas patologias, comparando seus sintomas, fatos, assim como semelhanças entre os casos clínicos descritos por Freud e os escutados no ambulatório de fibromialgia do Hospital de Clínicas, pode-se lançar a hipótese de que a fibromialgia não é uma doença contemporânea, mas sim um sintoma histérico contemporâneo.

No que diferem as pacientes de hoje e as histéricas de Freud? A serviço do que essa "nova" patologia aparece e ganha cada vez mais adeptos? Assim como a histeria, no século XIX, ela vem denunciar que algo precisa ser dito, revelado, colocado em palavras. Afinal é um corpo que fala, que dói.

$\mathrm{O}$ que faz a medicina hoje? Nomeia, descreve todo e qualquer sintoma que o ser humano possa sentir, ou pensar em sentir e então prescreve medicamentos. Como se a dor de viver aparecesse como dor física e pudesse ser medicada, curada com um analgésico.

Curiosamente na fibromialgia os medicamentos prescritos são antidepressivos, analgésicos, medicação para sono - tratamentos para dopar o corpo, calá-lo.

Quer-se calar o corpo para calarem-se as questões. Questões que devem ser trabalhadas, analisadas. A psicanálise surgiu, no século XIX, partir da busca de respostas ao enigma da histeria: descobriu um sujeito, desejante, que queria se fazer reconhecer. Sujeito esse que parece ter sido esquecido na contemporaneidade. Com a correria dos tempos modernos, em que a ciência e a tecnologia tentam dar conta de tudo, oferecendo objetos de gozo para qualquer falta, em que "tempo é dinheiro", as questões do viver ficam esquecidas ou prorrogadas. Mais uma vez, o corpo vem denunciar que não é assim que as coisas funcionam com o psíquico: sem a falta estruturante, não há surgimento do desejo, conseqüentemente, onde está o sujeito (\$)? Aquele que se implica, se questiona, põe suas dores em pauta? Se essa dor pode ser medicada, se esse corpo pode ser esquecido, se qualquer gozo é permitido, ainda assim podemos afirmar, a partir do discurso psicanalítico: é somente no campo simbólico, das palavras, que um sujeito pode tentar entender o que é ter um corpo, para exercer sua sexualidade e situar-se em um determinado lugar no mundo. 


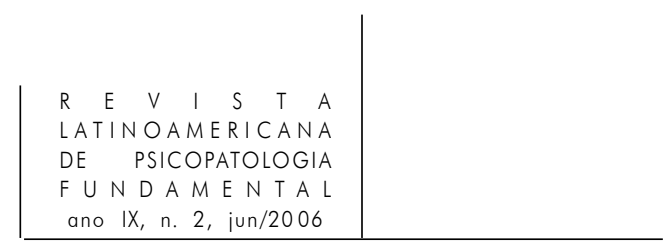

\section{Referências}

BennetT, R. M. Fibromyalgia and the facts: sense or nonsense. Rheum. Dis. Clin. North Am., 1993. Disponível em: <http://www.fibromialgia.com.br>. Acesso em: 28 abr. 2004.

Calligaris, C. Dores do espírito e dos músculos. Folha de S. Paulo, 5/4/2001.

Freud, Sigmund (1888). Histeria. In: Edição Standard Brasileira das Obras Psicológicas Completas de Sigmund Freud. Rio de Janeiro: Imago, 1996. v. 1.

(1893). Sobre os mecanismos psíquicos dos fenômenos histéricos: comunicação preliminar. In: Edição Standard Brasileira das Obras Psicológicas Completas de Sigmund Freud. Rio de Janeiro: Imago, 1996. v. 2.

(1893). Sobre os mecanismos psíquicos dos fenômenos histéricos: uma conferência. In: Edição Standard Brasileira das Obras Psicológicas Completas de Sigmund Freud. Rio de Janeiro: Imago, 1996. v. 3.

(1895). Estudos sobre a histeria. In: Edição Standard Brasileira das Obras Psicológicas Completas de Sigmund Freud. Rio de Janeiro: Imago, 1996. v. 2.

(1896). A etiologia da histeria. In: Edição Standard Brasileira das Obras Psicológicas Completas de Sigmund Freud. Rio de Janeiro: Imago, 1996. v. 3.

(1896). Carta 52. In: Edição Standard Brasileira das Obras Psicológicas Completas de Sigmund Freud. Rio de Janeiro: Imago, 1996. v. 1.

(1897). Carta 69. In: Edição Standard Brasileira das Obras Psicológicas Completas de Sigmund Freud. Rio de Janeiro: Imago, 1996. v. 1.

(1909). Cinco lições de psicanálise. In: Edição Standard Brasileira das Obras Psicológicas Completas de Sigmund Freud. Rio de Janeiro: Imago, 1996. v. 11.

Goldenberg, D. L. Fibromyalgia syndrome: an emerging but controversial condition. J. Am. Med. Assoc., 1987. Disponível em: <http://www.fibromialgia.com.br>. Acesso em: 28 abr. 2004.

Hench, P. K. Nonarticular rheumatism: twenty-second rheumatism review: of the American and English literature for the years 1973 and 1974. Arthritis Rheum., 1976. Disponível em: <http://www.fibromialgia.com.br>. Acesso em: 28 abr. 2004.

Hudson, J. I. \& Pope, Jr. H. G. Fibromyalgia and pshychopathology: is fibromyalgia a form of “affective spectrum disorder?”. J. Rheumatol., 1989. Disponível em: <http:// www.fibromialgia.com.br>. Acesso em: 28 abr. 2004.

JACoBsson, L. The commonest rheumatic complaints of over six weeks duration in a defined Swedish population. Scand. J. Rheumatol., 1989. Disponível em: <http:// www.fibromialgia.com.br>. Acesso em: 28 abr. 2004.

MartinEz, J. E. Fibromialgia: aspectos clínicos socioeconômicos. Rev. Bras. Reumatol., 1992. Disponível em: <http://www.fibromialgia.com.br>. Acesso em: 28 abr. 2004. 
Melman, Charles. Novas formas clínicas no início do terceiro milênio. Porto Alegre: CMC, 2003.

MoLdofsky, H. Musculoskeletal symptoms and non REM sleep disturbance in patients with fibrositis syndrome and healthy subjects. Psychosom. Med., 1975. Disponível em: <http://www.fibromialgia.com.br>. Acesso em: 28 abr. 2004.

Sleep - Wake mechanisms in fibrositis. J. Rheumatol., 1989. Disponível em:

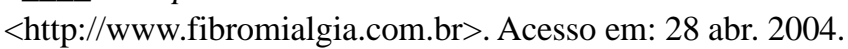

Quimby, L.G. Fibromyalgia: generalized pain intolerance and manifold symptom reporting. J. Rheumatol., 1988. Disponível em: <http://www.fibromialgia.com.br>. Acesso em: 28 abr. 2004.

RusselL, I. J. Serum amino acids in fibrosits/fibromyalgia syndrome. J. Rheumatol., 1989. Disponível em: <http://www.fibromialgia.com.br>. Acesso em: 28 abr. 2004.

SEDA, H. Reumatismo: conceito - história - nomenclatura - classificação - epidemiologia. In: SedA, H. Reumatologia. 2.ed. Rio de Janeiro: Cultura Médica, 1982. Disponível em: <http://www.fibromialgia.com.br>. Acesso em: 28 abr. 2004.

Simms, R. W. \& Goldenberg, D. L. Symptoms mimicking neurologic disorders in fibromyalgia syndrome. J. Rheumatol., 1988. Disponível em: <http:// www.fibromialgia.com.br>. Acesso em: 28 abr. 2004.

Smythe, H. A. \& Moldofsky, H. Two contributions to understanding the "fibrositis" syndrome. Bull. Rheum., 1977. Disponível em: <http://www.fibromialgia.com.br>. Acesso em: 28 abr. 2004.

WolfE, F. The clinical syndrome of fibrositis. Am. J. Med., 1986. Disponível em: <http:/ www.fibromialgia.com.br>. Acesso em: 28 abr. 2004.

The American Colllege of Rheumatology 1990: criteria for the classification of fibromyalgia - Report of the Multicenter Criteria Comittee. Arthritis Rheum., 1990. Disponível em: <http://www.fibromialgia.com.br>. Acesso em: 28 abr. 2004.

The fibromyalgia and myofascial pain syndromes: a preliminary study of tender points and trigger points in persons with fibromyalgia myofascial pain syndrome and no disease. J. Rheumatol., 1992. Disponível em: <http://www.fibromialgia.com.br>. Acesso em: 28 abr. 2004.

Wolfe, F. \& Cathey, M. A. Prevalence of primary and secondary fibrositis. $J$. Rheumatol., 1983. Disponível em: <http://www.fibromialgia.com.br>. Acesso em: 28 abr. 2004.

Yunus, M. B. Psychological aspects of fibromyalgia syndrome: a component of the dysfunctional spectrum syndrome. Baillière’s Clinical Rheumatology, 1994. Disponível em: <http://www.fibromialgia.com.br>. Acesso em: 28 abr. 2004. 


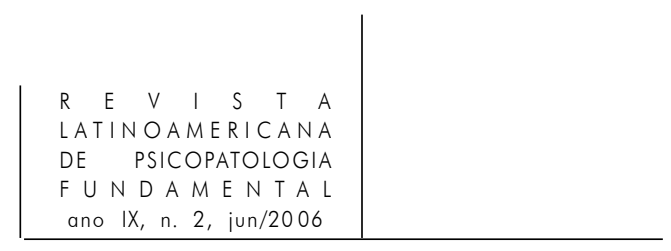

\section{Resumos}

Este trabajo tiene el objetivo de comparar el cuadro clínico contemporáneo Fibromialgía, con el cuadro clínico Histeria, tal cual fue descrito por Sigmund Freud en el siglo XIX. Pretende explorar las dos patologías en lo que se refiere a la descripción, síntomas, hechos y tratamiento. Serán también presentados casos clínicos para ilustrar los dos cuadros y identificar posibles semejanzas. La fibromialgía será descrita por medio del discurso médico contemporáneo, ya la histeria será abordada utilizando los escritos de Freud. Por fin, se defiende la hipótesis de que la fibromialgía hace parte del cuadro clínico de la histeria, o sea, que los sujetos diagnosticados con fibromialgia son en realidad pacientes que presentan síntomas histéricos.

Palabras claves: Fibromialgía, histeria, psicoanálisis

Le but de ce travail est comparer le tableau clinic contemporain de la fibromyalgie et le tableau clinic de l'hysterie décrit par Sigmund Freud dans le XIXe siècle. On vise à étudier les deux pathologies en ce qui concerne leurs descriptions, leurs symptômes, les histoires de vie des patients et leurs treatments. On présente des observations cliniques pour illustrer les deux tablexu clinics et répérer leurs ressemblances. La fiblomyalgie sera décrite à travers le dircours médical contemporain; l'hystérie, elle, sera traité à travers les écrits de Freud. Bref, on soutien l'hypothèse que la fiblomyalgie fait partie du tableau clinic de l'hysterie, c'est-à-dire, les sujets répérés comme ayant le diagnostic de fibromyalgie sont en fait des patients hysteriques.

Mots clés: Fibromyalgie, hysterie, psychanalyse

This article compares the contemporary pathology known as fibromyalgia with the disorder of hysteria as it was described by Sigmund Freud in the 19th century. It explores these two pathologies in their descriptions, symptoms, facts and treatment. Clinical cases are also presented in order to identify possible similarities. Fibromyalgia is described here in terms of contemporary medical discourse, whereas hysteria is viewed from Freud's work. Finally, the hypothesis is defended to the effect that persons with diagnosis of fibromyalgia in fact show symptoms of hysteria.

Key words: Fibromyalgia, hysteria, psychoanalysis

Versão inicial recebida em janeiro de 2006

Aprovado para publicação em março de 2006 